\title{
Strengthening school-based sexual and reproductive health education and services in Accra, Ghana
}

Nancy Termini LaChance

Population Council

Terence Adda-Balinia

Follow this and additional works at: https://knowledgecommons.popcouncil.org/departments_sbsr-rh

Part of the Demography, Population, and Ecology Commons, Family, Life Course, and Society Commons, International Public Health Commons, Maternal and Child Health Commons, and the Women's Health Commons How does access to this work benefit you? Let us know!

\section{Recommended Citation}

Termini LaChance, Nancy and Terence Adda-Balinia. 2017. "Strengthening school-based sexual and reproductive health education and services in Accra, Ghana," STEP UP Evidence Brief. Accra: Population Council. 


\section{Strengthening school-based sexual and reproductive health education and services in Accra, Ghana}

STEP UP generates policy-relevant research to promote an evidencebased approach for improving access to family planning and safe abortion.

We work in Bangladesh, northern India, Ghana, Kenya, and Senegal.

Population Council Coordinating Partner

African Population and Health Research Center icddr.b

London School of Hygiene and Tropical Medicine

Marie Stopes International

\section{Funded by}

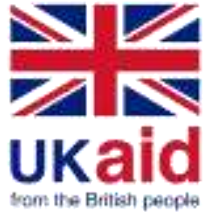

tem ite Bettah peeple

\section{INTRODUCTION}

Young people aged 10-19 years constitute about a quarter of the total population of Ghana. Although their knowledge of contraception has increased substantially over the past two decades $(85.7 \%$ had heard of any contraceptive method as of 1993, whereas $96.5 \%$ had by 2014) the majority still have inadequate and inaccurate knowledge about their sexual and reproductive health (SRH). ${ }^{1,4}$

When adolescents have poor knowledge of contraception and SRH, they engage in risky sexual behaviours. ${ }^{2}$ They have less information on protecting themselves from sexually transmited infections (STIs) and how to negotiate safe and consensual sex. Indeed, ignorance about sexuality and reproductive health among adolescents has been reported to increase early sexual debut as well as unplanned pregnancies. ${ }^{3}$

A 2015 STEP UP study in Ghana found that:

- $97 \%$ of parents interviewed supported the notion that SRH information and services be provided in schools;

- A third of adolescents were sexually active; of those, $15 \%$ had experienced forced sex;

- $80 \%$ of adolescents indicated that they desired additional SRH education in school. ${ }^{4}$

Based on these findings, STEP UP conducted a study to assess the feasibility and acceptability of providing comprehensive inschool SRH education to adolescents using trained psychologists and health workers to deliver and explain comprehensive sexuality education to adolescents and link them as needed to outside services. ${ }^{5}$
My view is they should provide sexual health services in schools, it is a world known issue now that we are having

girls getting pregnant in schools, but if these services had provided them I don't think they will find themselves in these situations."

(Education manager 2, KII)

\section{THE PROJECT}

The study aimed to assess the acceptability and feasibility of two proposed solutions for strengthening the content and delivery of in-school sexual and reproductive health programmes in Ghana. The study was conducted in Nima, a suburb of Accra.

A descriptive cross sectional study design was used, participants were selected through purposive sampling. A total of 79 students, 39 parents, and 18 teachers from two schools, along with 18 key informants (national and district level) were recruited.. Participants engaged in focus group discussions (FGDs) and in-depth interviews (IDIs). 


\section{RESULTS}

\section{Knowledge and views on adolescent $\mathrm{SRH}$ and information provision}

The findings suggested that neither adolescents nor parents had a full understanding of adolescent SRH issues. However, respondents agreed that there was a need to provide adolescents with SRH information, and acknowledgment that in the absence of accurate information, adolescents will rely on other potentially inaccurate sources of information on SRH.

\section{Sources of information on SRH}

Parents and teachers were identified as key providers of $\mathrm{SRH}$ information to adolescents. However, some parents lacked the knowledge, lacked the time, or felt hindered by societal norms, and teachers felt the additional task of SRH education would compete onerously with their other responsibilities. Electronic media and peers, relatives, churches, and mosques were also sources of SRH information. Overall, adolescents preferred to receive their SRH information from school or health workers. (Fig. 1).

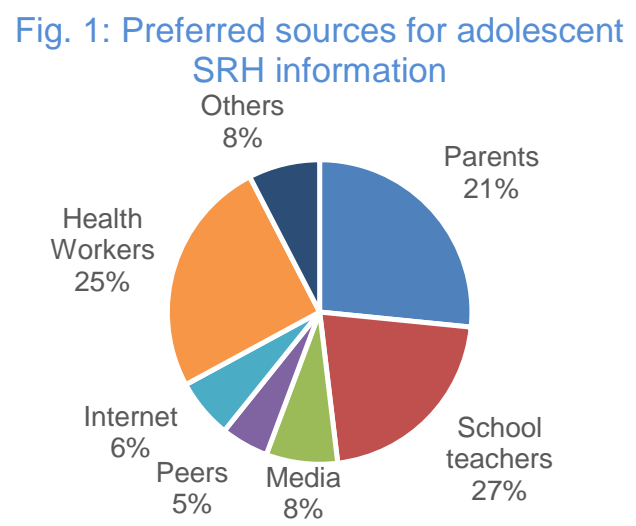

\section{Providing SRH information in schools} Both parents and students favorably perceived the use of psychologists and health workers to provide SRH information in schools. There was some concern as to whether this was a sustainable option (in terms of cost and availability of these individuals), and as to whether condom distribution would be acceptable especially in religious schools. It was suggested by several that community-based condom distribution would be better. However the overall impression was that with enough parental support, this strategy was good.

\section{Suggested citation:}

Nancy Termini LaChance, Terence Adda-Balinia. 2017. "Strengthening school-based sexual and reproductive health education and services in Accra, Ghana," STEP UP Evidence Brief, December 2017. Accra: Population Council.
It was also found that schools lacked a curriculum to teach population and family life education (POP/FLE) issues; creating a distinct POP/FLE course was felt to be a feasible and acceptable option to integreate SRH information into student education, and that meaningful stakeholder engagement would be necessary to determine appropriate content and implementation strategies.

\section{IMPACT \& MOVING FORWARD}

Recommendations from this study were nationally disseminated and discussed with stakeholders including Ministry of Education, Ghana Education Service, and UNFPA. It was based on the findings and discussion that Population Council was selected to be part of the National Stakeholder Group for the comprehensive sexuality educational reforms. The reforms (lead by the Ministry of Education and Ghana Education Services) will develop a national comprehensive sexuality education curriculum for the teaching of SRH issues in schools.

This study results have also directly informed a pilot study that seeks to assess comprehensive sexuality education in selected schools in the Central Region of Ghana. The implementation is led by Ghana Education Service, Ghana Health Service with support from the R3M program partners (Population Council, Marie Stopes International Ghana and Ipas). The study would also form the basis and reference for future research in Ghana on in-school comprehensive sexuality education for adolescents.

\section{CONCLUSION}

Stakeholders believed there was the need for enhanced $\mathrm{SRH}$ services in school. There was unanimous agreement that adolescent SRH needs are not being met; that schools provide the best opportunity to provide this education and service to adolescents; and that the two solutions under discussion were feasible and acceptable.

\section{WORKS CITED}

1. Ghana Statistical Service (GSS), Ghana Health Service (GHS), and ICF International. 2015. Ghana Demographic and Health Survey 2014. Rockville, Maryland, USA: GSS, GHS, and ICF International.

2. Blum RW \& Mmari KN. 2015. Risk and protective factors affecting adolescents reproductive health in developing countries. WHO \& Johns Hopkins Bloomberg School of Public Health.

3. Minnick D. J. \& Shandler L. 2012. Changing Adolescent Perceptions on Teenage pregnancy. Children \& Schools, 33(4), 241-248.

4. Esantsi $S$ et. al. 2015. Understanding the reproductive health needs of adolescents in selected slums in Ghana: A public health assessment. STEP UP Research Report. Ghana:Population Council.

5. Adda-Balinia T et. al. 2016. Acceptability and feasibility of introducing strengthened school-based sexual and reproductive health information and services in Accra, Ghana. STEP UP Research Report. Ghana: Population Council. 